\title{
O CORPO PRIMITIVO CONTEMPORÂNEO da/na margem não tecno(lógica)
}

\author{
EL CUERPO PRIMITIVO CONTEMPORÁNEO de/en el margen no \\ tecno(lógica)
}

\section{THE CONTEMPORARY PRIMITIVE BODY of/on the non-techno(logic) margin}

\section{Marcos Antônio Bessa-Oliveira ${ }^{1}$ \& Larissa Rodrigues ${ }^{2}$}

Resumo: Este trabalho emerge como pesquisa em Arte a partir de inquietações referentes às relações entre corpo, arte e tecnologia promovendo reflexões sobre a concepção de corpo na contemporaneidade. Entendendo que a tecnocolonização (RODRIGUES; BESSA-OLIVEIRA, 2019) emerge de um pensamento pós-moderno que insiste em desqualificar os corpos que não se inserem nos padrões de corpos-tecno(lógicos) contemporâneos, por meio da pesquisa bibliográfica e a partir das minhas vivências como discente do curso de Artes Cênicas, queremos impulsionar uma reflexão contramoderna em arte e tecnologia, destacando minha corpo-política (MIGNOLO, 2010), inscrita como sujeito periférico em relação aos grandes centros tecnológicos e de arte, como um produtor de arte, de cultura e de conhecimento. Evidenciando que a visão de um corpo preso e obediente à tecnologia implica uma supremacia e um discurso sobre o corpo que não devemos perpetuar, por meio desta pesquisa lhe convido então a experimentar um olhar sobre o seu íntimo

\footnotetext{
${ }^{1}$ Marcos Antônio Bessa-Oliveira é Professor na UEMS (nas Graduações em Artes Cênicas, Dança e Teatro e no PROFEDUC), é Coordenador do NAV(r)E - Núcleo de Artes Visuais em (re)Verificações Epistemológicas - UEMS/CNPq. ORCID iD: https://orcid.org/0000-0002-47837903. Email: marcosbessa2001@ gmail.com.

${ }^{2}$ Larissa Rodrigues é Graduada em Artes Cênicas pela UEMS. É membro do NAV(r)E - Núcleo de Artes Visuais em (re)Verificações Epistemológicas - UEMS/CNPq. E-mail: laris.larry@gmail.com.
} 
individual, você que é feito de carne e sangue, dotado de percepções, desejos, instintos e potencialidades, promovendo uma pequena amostra do que está guardado em todos nós e que a tecnologia não tem o poder de extinguir as nossas biogeografias (BESSA-OLIVEIRA, 2016).

Palavras-chave: Arte; Tecnologia; Corpo-política.

Resumen: Este trabajo surge como investigación en Arte a partir de preocupaciones sobre las relaciones entre cuerpo, arte y tecnología promoviendo reflexiones sobre el concepto de cuerpo en la época contemporánea. Entender que la tecnocolonización (RODRIGUES; BESSA-OLIVEIRA, 2019) surge de un pensamiento posmoderno que insiste en descalificar cuerpos que no encajan en los patrones de los tecnocuerpos(lógicos) contemporáneos, a través de la investigación bibliográfica y de mis experiencias como estudiante de el curso de Artes Escénicas, queremos incentivar una reflexión contramoderna en el arte y la tecnología, destacando mi cuerpo-política (MIGNOLO, 2010), inscrito como asignatura periférica en relación a los grandes centros tecnológicos y artísticos, como productora de arte, cultura y conocimiento. Evidenciando que la visión de un cuerpo atrapado y obediente a la tecnología implica una supremacía y un discurso sobre el cuerpo que no debemos perpetuar, a través de esta investigación te invito a experimentar una mirada a tu íntimo, tú que estás hecho de carne y hueso, dotado de percepciones, deseos, instintos y potencialidades, promoviendo una pequeña muestra de lo que todos tenemos almacenado y que la tecnología no tiene el poder de extinguir nuestras biogeografías (BESSAOLIVEIRA, 2016).

Palabras clave: arte; Tecnología; Cuerpo-política.

\begin{abstract}
This work emerges as research in Art from concerns regarding the relationships between body, art and technology promoting reflections on the concept of the body in contemporary times. Understanding that technocolonization (RODRIGUES; BESSA-OLIVEIRA, 2019) emerges from a postmodern thought that insists on disqualifying bodies that do not fit into the patterns of contemporary (logical) techno-bodies, through bibliographic research and from the my experiences as a student of the Performing Arts course, we want to encourage a countermodern reflection in art and technology, highlighting my body-politics (MIGNOLO, 2010), inscribed as a peripheral subject in relation to the great technological and art centers, as an art producer, culture and knowledge. Evidencing that the vision of a body trapped and obedient to technology implies a supremacy and a discourse about the body that we must not perpetuate, through this research I invite you to experience a look at your intimate individual, you who are made of flesh and blood, endowed with perceptions, desires, instincts and potential, promoting a small sample of what is stored in all of us and that technology does not have the power to extinguish our biogeographies (BESSA-OLIVEIRA, 2016).
\end{abstract}

Keywords. Keyword: Art; Technology; Body-politics. 


\section{INTRODUÇÃO - O corpo que sente, faz e sabe!}

Desprender-se significa não aceitar as opções que lhe brindam. Não pode evitá-las, mas ao mesmo tempo não quer obedecer. Habita a fronteira, sente na fronteira e pensa na fronteira no processo de desprender-se e resubjetivar (MIGNOLO, Desafios descoloniais hoje, p. 19).

Este trabalho é o desdobramento de uma pesquisa que pretende provocar a reflexão acerca do corpo contemporâneo que vivencia a era da tecnocolonização (RODRIGUES; BESSA-OLIVEIRA, 2019) e como esse contexto na Arte vem desconstruindo o pensamento moderno de que o corpo é obsoleto e "preso" à tecnologia, transformando em obsoleta a própria ideia de que a matéria biológicacultural-social é mero instrumento da tecnologia. ${ }^{3}$ A partir de pesquisa bibliográfica buscamos impulsionar uma discussão em Arte e tecnologia aliada ao meu percurso como discente do curso de Licenciatura em Artes Cênicas na Universidade Estadual do Mato Grosso do Sul, Unidade Universitária Campo Grande.

Somos levados a acreditar todos os dias que estamos desumanizados, anestesiados, quando na verdade só nos é permitido ser corpo contemporâneo quando o pós-modernismo entende que esse corpo da diferença cultural é um protótipo de corpo, ou seja, apenas por meio de discursos hegemônicos do biopoder (FOUCAULT, 1987) e do controle do sujeito de poder ser descolonial que esses corpos subalternizados são postos à qualidade de contemporâneos, de ser mais. Colocando em detrimento todos os corpos das margens não

\footnotetext{
${ }^{3}$ Juntamente com o orientador desta pesquisa, tenho trabalhado na construção da reflexão que leva à compreensão melhor desse termo tecnocolonização por algumas razões que não a puramente de um corpo na arte vinculado à tecnologia enquanto arcabouço de criação/encenação. Queremos discutir por meio de conceituação epistemológica outra a ideia de que a tecnologia é também uma forma de poder que gera dependência para alguns corpos bem como o é um mecanismo de controle de corpos que não querem se render à tecnologia. Quer dizer, ora temos a tecnologia como prolongamento dos corpos, ora é a tecnologia quem quer encarcerar corpos que não se prendem à necessidade desta. Neste último caso, portanto, podemos dizer que são corpos que estão rompendo com a lógica geo, teo e historiográfica da colonização: Europa (séc. XV) e Estados Unidos (séc. XX) cristãos e ainda estão libertando-se da tecnologia como o mais novo processo de colonização: a tecno(lógica) da tecnocolonização.
} 
tecno(lógicas) que não fazem parte dessa tecnocolonização, visto que o acesso não é democratizado. ${ }^{4}$

Entretanto, o corpo, ao mesmo tempo em que segue utilizando os aparatos tecnológicos, sente a necessidade de recorrer aos seus instintos mais primitivos, nos mostrando que existe o elo que liga corpo instintivo e corpo tecnológico e que, por meio das Artes da Cena assume novas formas de expressão. ${ }^{5}$ Se a partir da perspectiva pós-moderna o corpo da contemporaneidade só é contemporâneo porque participa da tecnocolonização, por meio da perspectiva descolonial podemos dizer que ele é primitivo contemporâneo porque tem a consciência de que sente, faz e sabe entendendo que o corpo biogeográfico (BESSA-OLIVEIRA, 2017) não pode mais ser condicionado ao mero depósito da tecnocolonização.

Para melhor compreensão de nossas reflexões estabelecemos a ideia de corpo primitivo contemporâneo, assim como refletimos sobre a sociedade da informação e as consequências e paradoxos derivados do advento da globalização e da cibercultura como agentes provocadores da tecnocolonização (RODRIGUES; BESSA-OLIVEIRA, 2019). Em seguida há um relato referente à experiência do meu corpo primitivo contemporâneo, no curso de Licenciatura em Artes Cênicas da Universidade Estadual de Mato Grosso do Sul, do qual traço um paralelo entre as minhas vivências, percepções/sensibilidades e a concepção do que, de fato, é entendido por arte, evidenciando minha corpo-política (MIGNOLO, 2010).

4 O tecno(lógicas) refere-se à ideia de que o corpo contemporâneo deve, logicamente, considerando nosso contexto atual, fazer uso e ser suporte da tecnologia. Assim, o corpo que não se tecnologiza, vamos dizer assim, por meio de aparatos virtuais - redes sociais, aparelhos eletrônicos contemporâneos, entre outros -, pode-se dizer, não existe.

${ }^{5}$ Parece curiosa essa ideia de argumentar acerca de um corpo primitivo em pleno século XXI. Mas esta questão se deve ao fato de que os corpos de consciência descolonial estão se voltando para a Natureza, um retorno em que impera a razão-sensação-emoção enquanto condição indissociável. Logo, é uma questão primitiva no íntimo mais recôndito do corpo "humano e animal", mas o é também a consciência de que o domínio sobre a Natureza não tem nos levando aos melhores resultados de "convivência" enquanto sujeitos que dependem dela para sobreviver. Do mesmo modo a questão da "expressão" se inscreve neste trabalho sob a perspectiva da existência/insistência do corpo, não da produção de um corpo-tecno-ou-não-(lógico).

Cadernos de estudos culturais, Campo Grande, MS, v. 2, p. 137-160, jul./dez. 2020. 
Portanto, queremos promover uma reflexão contramoderna ${ }^{6}$ a respeito de arte, de corpo e de tecnologia entendendo que a visão de um corpo preso à tecnologia é moderna, visto que implica uma supremacia sobre o corpo que não devemos perpetuar. Por meio desta pesquisa, lhe convido a experimentar então um olhar sobre o seu íntimo individual, você que é feito de carne e sangue, dotado de percepções, desejos, instintos e potencialidades, promovendo uma pequena amostra do que está guardado em todos nós e que nem mesmo a tecnologia tem o poder de extinguir: as nossas biogeografias (BESSA-OLIVEIRA, 2016).

$\mathrm{Na}$ primeira ordem, essas biogeografias seriam, considerando o suposto aparato e amparo que as tecnologias dão aos corpos contemporâneos, a corpopolítica que são corpos primitivos contemporâneos que não se rendem à tecnologia por compreendê-la mais como uma tecnocolonização de corpos que devem estar a serviço dos poderes instituídos pelo estado-nação ou pelas corporações que estabelecem que o corpo deva crescer, para trabalhar e consumir

\footnotetext{
${ }^{6}$ A ideia de (re)verificar ou (re)verificação ou de contramoderno grafados nesta pesquisa não tem nenhuma relação com a ideia de reverificar pensamentos postos a fim de mantê-los. Menos ainda de fazer valer aquelas ideias modernas de construção de um pensamento unilateral. Muito pelo contrário, a predisposição do (re) ou de contras nas grafias apresentadas nesta e em outras pesquisas vinculadas ao NAV(r)E - Núcleo de Artes Visuais em (re)Verificações Epistemológicas - UEMS/CNPq - tem intenção primeira de fazer valer a ideia de que algumas colocações teóricas avançaram e muitas retrocederam para pensar as proposições artístico-culturais, crítico, teórica e pedagógicas da América Latina. Portanto, estamos ancorados na lógica de Boaventura de Sousa Santos (1999) quando diz NÃO ao epistemicídio, e pensamos isso mesmo em relação ao pensamento descolonial. Assim, bem como esta pesquisa, a tentativa do grupo de pesquisa, certificado pela UEMS - Universidade Estadual de Mato Grosso do Sul junto ao CNPQ Conselho Nacional de Desenvolvimento Científico e Tecnológico, NAV(r)E - NÚCLEO DE ARTES VISUAIS EM (re)VERIFICAÇÕES EPISTEMOLÓGICAS, é romper criticamente com qualquer noção binária de pensar as produções em Artes Visuais - indistintamente da linguagem (plástica, performática, cênica, escultórica etc). A proposição dos pesquisadores envolvidos no grupo é a de podermos fazer reflexões teóricas que pensem sem exclusividade (Lugar Nenhum) como centro, mas que têm um lócus tomado como ponto de partida (o estado de Mato Grosso do Sul (na fronteira Brasil/Paraguai/Bolívia)) das reflexões para pensar em (Lugares Todos), especialmente latino-americanos como produtores de saber. Pensamos assim já que a ideia é fazer (re)Verificações Epistemológicas das produções artístico-visuais de lugares com características fronteiriças (geográfico e culturalmente falando) tomando as formulações teórico-críticas da crítica biográfica, estudos pós-coloniais e da crítica cultural embasando as reverificações teórico-críticas levantadas.
}

Cadernos de estudos culturais, Campo Grande, MS, v. 2, p. 137-160, jul./dez. 2020. 
e conseguir sobreviver em sociedade tecnológica/consumista. Logo, o corpo primitivo na contemporaneidade de que trato, que pode até remeter à ideia equivocada pré-histórica de corpo primitivo sem os aparatos tecnológicos disponíveis na atualidade, é, na verdade, aquele corpo que não se quer vinculado e dependente da tecnologia do encarceramento digital/virtual para conviver.

\section{CORPOS DAS MARGENS não tecno(lógicas)}

Neste exato momento em que começo a escrever esses registros, o meu sistema olfativo é acionado por meio da neurorrecepção que se transforma em um agradável cheiro do que conhecemos como "Sopa paraguaia", , trata-se da minha mãe Tania desempenhando uma ação que foi-lhe ensinada por meio da herança cultural, ou seja, neste caso, passada de avó para neta. Herança que não se aplica a mim visto que sempre estive na contramão do forno de barro ou na do forno a gás, privilegiando o uso do forno micro-ondas devido à sua praticidade, atendendo de forma veloz as vontades de uma nativa digital.

Segundo o norte-americano Marc Prensky (2001), as pessoas que nasceram após os anos 80 são consideradas nativos digitais, tendo o seu desenvolvimento biológico e social em contato direto com a tecnologia, apresentando uma relação de domínio em afinidade à utilização de aparatos tecno(lógicos), fato que foi e continua sendo intensificado a cada novo amanhecer no século XXI. Logo, as pessoas que nasceram antes da década de 1980 "viram" o mundo se transformar a partir de um poderoso processo de tecnocolonização (RODRIGUES; BESSAOLIVEIRA, 2019) em/nos seus corpos.

Se a minha bisavó Isabel fazia a sopa paraguaia em um forno de barro à lenha conhecido na cultura local como tatakuá ${ }^{8}$ e fez uso dele até o fim de sua vida em meados de 1993. A minha mãe, mesmo conhecendo e dominando a técnica do forno de barro, após adquirir o fogão e forno elétricos passou a utilizálos durante o processo de cozimento/execução da sopa, transformando o ritual em

\footnotetext{
7 Bolo de fubá de milho salgado, considerado prato tradicional da cultura Paraguaia, muito presente na cultura sul-mato-grossense.

${ }^{8}$ Forno de barro em Guarani ainda muito usado na linha de fronteira Brasil/Paraguai nas cidades divisas/próximas Ponta Porã-BR e Pedro Juan Caballero-PY.
} 
uma ação com maior praticidade, utilizando os mesmos ingredientes, porém com uma ferramenta elétrica, se privando de uma experiência que demanda tempo hábil.

Aquecer o forno de barro, buscar a lenha, colocar a lenha no forno, ascender o fogo, esperar a reação do fogo, esperar, esperar por aproximadamente três horas. Esperar o forno aquecer, colocar óleo e cebola em uma panela, levar ao fogo, esperar fritar, em seguida acrescentar fubá, leite e o queijo, mexer até que se forme uma massa homogênea, pegar uma assadeira, despejar a massa na assadeira e reservar. Olhar o forno e se estiver bem aquecido (dedução feita a olho nu) retirar a brasa com um tipo de vassoura que é feita de raízes e galhos de plantas, despejar a brasa no chão, jogar água, mais água até evaporar, pegar a massa da sopa, levar ao forno, cuidar a sopa por cerca de 40 minutos, retirar com cuidado, esperar esfriar, retirar da forma/assadeira e servir para finalmente comer.

O verbo "esperar" parece ter seus dias contados no mundo contemporâneo, justamente porque a relação espaço-tempo assume uma nova configuração, onde 24 horas de um dia são insuficientes para a demanda cotidiana de um humano contemporâneo. É esse cenário que vivenciamos, optando sempre para o que é mais rápido o que de certa forma facilita o nosso dia a dia. Fatos que compartilho nesta pesquisa com intuito de exemplificar como a tecnologia, desde a considerada mais simples hoje, no caso dos eletrodomésticos, exercem uma mudança sociocultural no cotidiano da espécie humana e consequentemente nos corpos que vivenciam a era tecnológica, o ciberespaço e a cibercultura, nos fazendo repensar o corpo e o espaço que habitamos como enfatiza Gabriela Salvador:

Esse espaço virtual, que o corpo passa a "habitar", mudou a maneira de o homem se relacionar com o mundo, além de expandir os limites e possibilidades em muitas pesquisas sobre o corpo, bem como sobre sua comunicação e expressividade. Esse ciberespaço é explorado de diversas maneiras na dança contemporânea atual, que o utiliza infinitamente em suas criações, acrescentando relações de tempo e espaço bem mais complexas do que as até então conhecidas. Os espetáculos contemporâneos usam as novas tecnologias alterando a percepção - tanto dos artistas quanto dos espectadores - do corpo, mudando o olhar, canalizando a atenção e colocando o corpo em um espaço diferenciado do que antes era costume, dandolhe a possibilidade de se transformar, até mesmo, em outros corpos ou outros objetos (SALVADOR, 2011, p. 25-26).

Ao se pensar esse contexto nas Artes Cênicas, meu lugar de fala, é inegável dizer que as linguagens da Dança e do Teatro andam na contramão em relação ao 
que é imposto sobre o corpo, mesmo que os discursos homogeneizantes sobre arte insistam em desqualificar os corpos das margens não-tecno(lógicas). É justamente a consciência de ser e estar da/na margem que me leva a entender o meu corpo como um produtor de epistemologias que emergem do meu contexto, sobretudo da prática enquanto artista-docente-pesquisadora. Sendo assim, acredito no que Walter Mignolo diz a respeito da margem:

A "fronteira da civilização" em fins do século 19 tornou-se a "margem" do fim do século 20. Margens, ao contrário de "fronteiras", não são mais linhas onde se encontram e dividem civilizações e barbárie, mas o local onde uma nova consciência, uma nova gnose liminar, emerge da repressão acarretada pela missão civilizadora (MIGNOLO, 2003, p. 404).

É por meio da prática e da consciência corporal durante a minha formação que pude compreender o meu corpo da diferença cultural como um produtor de arte, de cultura e de conhecimentos outros. Logo, acredito que discutir sobre a desumanização que o corpo biológico está sofrendo, atribuída a ascensão tecnológica, na contemporaneidade, como reforça a teorização pós-moderna, tratase de uma reflexão e de discurso que não me servem mais! Justamente porque partem de uma premissa de que apenas reforça a ideia moderna de corpo como depósito.

Aqui estou argumentando contra a ideia de que o corpo é dependente na atualidade do uso da tecnologia contemporânea a fim de promovê-lo à atualização (sobrevida do corpo subalterno) no contexto global digital. Igualmente me refiro à noção de que o corpo tecnológico tornou-se um corpo desumanizado, por isso o corpo é atualizado - andrógeno em algumas linguagens para se manter em consonância com as obrigações/imposições da tecnocolonização. Logo, esse suposto corpo atual, nunca primitivo neste contexto de Era Digital e de virtualização é um corpo que depende dos complementos (por meio de um celular (smartphone), uma rede social ou mesmo de recursos computadorizados até no seu dia a dia doméstico e ainda de veículos cada vez mais "humanizados" por meio de inteligências artificiais) que são controlados pelos mesmos promotores dos projetos de universalização (séc. XV europeu) e de globalização (estadunidense séc. XX).

O objetivo deste trabalho configura-se em ir além de ideias modernas e também pós-modernas, promovendo uma reflexão contramoderna a respeito de arte, corpo e tecnologia. Ao invés de falarmos da anestesia corporal contemporânea, iremos nos atentar a expressividade, estesia, a latência, potência e 
a existência viva do corpo da contemporaneidade, vivenciada por mim nas Artes Cênicas. Sendo assim, acredito que o pensamento de Helena Katz e Christine Greiner em relação à ideia de corpomídia (KATZ; GREINER, 2005) contribui para a imagem de corpo que refletimos nesses escritos:

O corpo vive no estado do sempre-presente, o que impede a noção do corpo recipiente. $\mathrm{O}$ corpo não é um lugar onde as informações que vêm do mundo são processadas para serem depois devolvidas ao mundo. O corpo não é um meio por onde a informação simplesmente passa, pois toda informação que chega entra em negociação com as que já estão. O corpo é o resultado desses cruzamentos, e não um lugar onde as informações são apenas abrigadas (KATZ; GREINER, 2005, p. 7).

O corpomídia rompe com a ideia tradicional que foi imposta pelo pensamento moderno, a dicotomia corpo e mente nos apresentando um corpo em fluxo que é parte da natureza em constante diálogo de troca, em uma infinita correlação de atravessamentos. Embora o homem seja tecnológico por essência, visto que molda a natureza a partir das suas necessidades, desde sempre, é exatamente a consciência de que o seu corpo vive em constante fluxo de trocas do/no lugar ao qual pertence que o torna dono de seu próprio tempo.

Portanto, é de suma importância deixar claro que a relação entre corpomídia e corpo primitivo contemporâneo está no pensamento de corpo soma, ou seja, o corpo como unidade, livre da dicotomia corpo físico/corpo psíquico como diz Gabriela Salvador:

Soma aqui é um conceito que entende que não se separa o corpo físico do corpo psíquico, emocional e espiritual. O corpo que é soma está em constante troca com o ambiente, com a sociedade, com a cultura e com as experiências por ele vividas (SALVADOR, 2010, p. 1).

Ao refletir sobre o meu corpo primitivo contemporâneo, esse corpo que é soma e que está em constante processo de troca e compartilhamento percebo um poderoso processo de tecnocolonização, conceito que queremos discutir por meio desta pesquisa.

Mas do que se trata a tecnocolonização?

Durante o desenvolvimento desta pesquisa, que apresenta uma revisão bibliográfica aliada às experiências que tive durante a formação em licenciatura em Artes Cênicas, sobretudo as experivivências que hoje complementam e compõem a artista-docente-pesquisadora que sou, juntamente com meu professor 
orientador Dr. Marcos Antônio Bessa-Oliveira, chegamos à grafia do conceito que une tecnologia e colonização: tecnocolonização.

A tecnocolonização é uma intersecção entre o processo colonizador na contemporaneidade que é provocado a partir das estruturas, sistemas e discursos de poder oriundos da tecnologia. Esses discursos do tecnopoder, podemos dizer assim, insistem em desqualificar os corpos da contemporaneidade que não se inscrevem nos padrões midiáticos, digitais e formais, por isso tecno(lógicos), como ultrapassados e obseletos, reforçando a ideia moderna de corpo que subjulga a matéria biológica-cultural-social e suas potencialidades naturais à meros coadjuvantes no que tange a arte, a cultura e ao conhecimento provocando uma colonização tecnológica, econômica, política social e até sensitiva/subjetiva.

A reflexão está também baseada nas discussões descoloniais que entendem o mundo ocidental a partir das implementações de diferentes geopolíticas do poder que sempre estão nas mãos dos países primeiro-mundistas: geopolítica energética, geopolítica do conhecimento, geohistórica, geoteologia, geografia política, geopolítica cultural, geopolítica da arte, geopolítica do alimento, sexual, de língua, de raça, de classe, gênero, de corpo, entre muitas outras que classificam o mundo em centros do poder e margens que obedecem. Logo, essas discussões não se concentram em binarismos que discutem simplesmente centros versus periferias, mas a instauração de poderes e desempoderamentos por meio agora da tecnocolonização.

\section{O CORPO PRIMITIVO contemporâneo}

A contemporaneidade nos sugere diversas e inesgotáveis fontes de conhecimentos, principalmente quando o instrumento para o saber se dá por meio da utilização de aparatos tecnológicos que têm o poder de transformar tudo que um dia já foi inacessível em acessibilidade concreta, mesmo que virtualmente. Portanto, falar de um corpo contemporâneo consiste em refletir para além da matéria biológica do agora, onde podemos dizer que o smartphone funciona como uma extensão corporal e este corpo e o mundo se encontram em constante transformação, na tentativa de suprir as necessidades e vontades do humano contemporâneo.

Pode dizer-se contemporâneo apenas quem não se deixa cegar pelas luzes do século e consegue entrever nessas a parte da sombra, a sua ínfima obscuridade. Por que

Cadernos de estudos culturais, Campo Grande, MS, v. 2, p. 137-160, jul./dez. 2020. 
conseguir perceber as trevas que provêm da época deveria nos interessar? Não é talvez o escuro uma experiência anônima e, por definição, impenetrável, algo que não está direcionado para nós e não pode, por isso, nos dizer respeito? Ao contrário, o contemporâneo é aquele que percebe o escuro do seu tempo como algo que lhe concerne e não cessa de interpelá-lo, algo que, mais do que toda luz, dirige-se direta e singularmente a ele. Contemporâneo é aquele que recebe em pleno rosto o facho de trevas que provém do seu tempo (AGAMBEN, 2009, p. 63-64).

Ao perceber o facho de trevas que advém do meu tempo, que insiste em desqualificar o meu corpo como um produtor de arte, cultura e conhecimento, que o impõe a condição de ser menos perante a tecnocolonização, busco por meio desta pesquisa (re)afirmar o meu lugar enquanto corpo biogeográfico (BESSA-OLIVEIRA, 2017) que sente o que faz, que faz porque sente e sabe o que está fazendo, tornando-o corpo primitivo contemporâneo de seu próprio tempo. O contemporâneo, portanto, é aquele que percebe o seu tempo em distinção do passado como um tempo em que se constitui enquanto corpo: é nesta lógica que ainda nos serve Giorgio Agamben. Sobretudo, evidenciar uma consciência outra que foi apresentada a mim por meio da prática corporal durante a formação de Licenciatura em Artes Cênicas. Sendo assim, compartilho do pensamento de Edgar Nolasco:

Se a boutade moderna "penso, logo existo" ancorou a ordem do discurso científico moderno, com a insurgência de epistemologias outras estamos todos aprendendo hoje que sentimos, vivemos, estamos sendo e pensamos numa desordem epistemológica que contribui para a quebra de hierarquias e de ideias totalizantes, homogeneizantes, puristas e abstratas. (Abrindo um parêntese, é como se dissesse que as pesquisas, ou melhor, os resultados das pesquisas públicas realizadas, não podem mais servir apenas para decorar bibliotecas e estantes empoeiradas, mas devem contribuir com as diferenças e preconceitos que ainda grassam dentro da academia, nas ruas das cidades e na sociedade em geral.) (NOLASCO, 2019, p. 4).

Portanto, torna-se indispensável refletir sobre o mundo em que nos encontramos e vivenciamos hoje. Veremos o tempo e espaço dominados por corpos e culturas específicas, evidenciando a matéria biológica como instrumento de imposições. E ao falar do corpo primitivo contemporâneo se faz necessário questionar as imposições que foram concretizadas por meio de discursos do poder, levando em consideração o lócus enunciativo desses pensamentos impositivos que predominam na contemporaneidade, manipulando e ditando o que é arte, quem é cultura e o que gera conhecimentos, delimitando e submetendo corpos contemporâneos a corpos 
dóceis (FOUCAULT, 1987). A partir disso, Marina Simão contribui quando ressalta:

Por biopoder, compreendo, a partir de Foucault (1987), como a prática do poder aplicada à vida dos indivíduos, enquanto coletivo, para o controle da espécie. Tratase de um conceito aplicado ao coletivo para designar o controle naquilo que os indivíduos têm em comum, a vida. Assim, os objetos de saber são criados a fim de servir o poder, controlar os corpos. O biopoder atua através da força disciplinar, controlando e formatando os corpos, e a resistência, embora por oposição, não exclui o corpo das consequências das relações de poder. As redes sociais apresentam técnicas que, dentro dos processos disciplinares, tornam o corpo mais útil conforme se torna mais obediente e vice-versa (SIMÃO, 2017, p. 23-24).

Esta relação de biopoder é diretamente semelhante aos princípios da cibernética, onde o controle dos corpos e dos cibercorpos são executados por meio da utilização de aparatos tecnológicos. E um grande exemplo é a China que condicionou a sua população a um grande "Big Brother" a céu aberto, outro são os Estados Unidos com seus escândalos de espionagem universal. Controlar corpos sempre foi uma condição impositiva para o domínio, a marginalização e subalternização, visto que o corpo é morada de potencialidades múltiplas.

Mas será que somos mesmo corpos dóceis habitando a contemporaneidade e vivendo sobre enraizamentos medievais? Ou será que esta é mais uma história contada sobre o corpo a fim de dominá-lo? Acredito que somos corpos primitivos contemporâneos vivendo sobre um pensamento medieval que advém da sociedade, uma instituição que insiste em promover os discursos hegemônicos, subjugando o corpo à qualidade de ser menos, um corpo que vem tentando se inscrever na contemporaneidade por meio de discursos do biopoder.

Por exemplo, não sou uma pessoa que se inscreve no padrão social da atualidade, não tenho instagram e utilizo muito pouco às redes sociais, fato que é considerado praticamente uma heresia, me condicionando a um ser/corpo sem identidade, suspeito e não tecno(lógico). Logo, posso dizer que sou esse corpo primitivo contemporâneo que "habita" a condição não tecno(lógica)!

Mas o que de fato queremos discutir aqui são as relações do corpo contemporâneo, o corpo que não pode ser pensando sem um olhar direto para a tecnologia, haja vista que esse corpo está vivenciando todas as consequências da era da virtualização e da aceleração tecnológica na arte, na cultura e na produção de conhecimentos. O que acaba por nos levar aos seguintes questionamentos: Como o corpo primitivo contemporâneo se configura na Arte? Esse corpo está se 
configurando como um corpo que repete? Como um corpo que obedece? Ou se constitui como um corpo que tem domínio sobre si próprio?

O termo "primitivo contemporâneo" que queremos difundir por meio desta pesquisa trata-se do corpo biológico, inerentemente dotado de potencialidades naturais: percepções, sensações, sentidos, instintos na contemporaneidade, ou seja, o corpo do "agora" e sua relação com a Era da virtualização, a cibercultura e seu elo com o que é entendido por primitivo, por estar ligado às relações sensoriais inerentes ao ser humano. Contudo, quero deixar claro que o termo primitivo contemporâneo não se trata de um conceito cartesiano, na tentativa de definir a tão complexa e diversa matéria corporal, mas sim de uma ilustração para as camadas de relações e sensações que irei relatar.

Levando em consideração meu lócus enunciativo, a cidade de Campo Grande, Mato Grosso do Sul, região considerada periférica em relação aos grandes centros do país (São Paulo, Rio de Janeiro, Belo Horizonte...), acredito que esta pesquisa já evidencia minha corpo-política (MIGNOLO, 2010), estereotipada como "interiorano", visto como inferior no que tange a arte, cultura, conhecimento e consequentemente à tecnologia, buscando seu direito de fala.

A minha inquietação referente ao corpo e a tecnologia parte da ideia de refletir sobre esse corpo do "agora" que é visto como um corpo tecnocolonizado sofrendo de uma anestesia corporal, sendo definido, limitado e estereotipado à qualidade de máquina, mas que tem suas potencialidades perceptivas, sensoriais despidas, elucidadas e reverenciadas por meio da arte. Por este motivo proponho, por meio dessas páginas, o pensamento de desprender-se da colonização moderna. Também desconstruir o pensamento pós-moderno de que a matéria biológica social é um instrumento que apenas repete aos comandos dados.

O corpo está em constante relação com o mundo exterior, pela pele ou pela roupa através da matéria corporal transformamos o meio e somos transformados, desenvolvendo processos cognitivos como enfatiza Andréa Bergallo Snizek:

O corpo transita, flutua, como e/com os pensamentos, é afetado e afeta o "meio", experimentando as mudanças constantes que promove e às quais se submete, inaugurando, desencadeando e desenvolvendo processos cognitivos (2014. p. 47).

Assim como é inegável que as tecnologias estão mudando as formas que o ser humano ensina, aprende, pensa e se expressa, sobretudo como se coloca e se vê no mundo, configurando-se como um ser complexo: é notável a busca coletiva 
e individual por autoconhecimento, emoção e liberdade. Sendo o ato de se expressar um meio pelo qual as pessoas conseguem alcançar níveis de autoconhecimento e liberdade. E é nas artes que o humano encontra uma abertura para refletir, experimentar e expor suas opiniões e desejos. Portanto, é de suma importância a reflexão de como o corpo da contemporaneidade se configura na arte, este corpo que pulsa, sente e emana, um corpo que é constantemente atravessado pela tecnologia.

Então, compreendo que não somos como "corpos dóceis" de Michel Foucault (1987), corpos submissos à (re)produção dos mesmos conhecimentos e da manutenção do discurso de ser e ensinar a ser corpo. Por isso, venho dar visibilidade ao corpo primitivo contemporâneo apresentando-o como produtor de arte, cultura e conhecimento outros, resignificando a visão estereotipada de corpo obediente sobre os corpos que habitam a contemporaneidade. Promovendo uma reflexão que te leve a desprender-se da ideia imposta de corpo submisso à tecnologia, não negando a tecnocolonização, mas estimulando uma consciência de que para ser um corpo contemporâneo é necessário questionar, repensar e reconfigurar o pensamento pós-moderno que impera sobre nossos corpos.

Assim, a corpo-política é o lado negro e a metade faltante da biopolítica que é apenas a metade da história: a corpo-política descreve as tecnologias descoloniais aplicadas aos corpos que se dão conta que foram considerados menos humanos, no momento em que tomam consciência de que o ato mesmo de ser descritos como menos humanos era uma consideração inumana. Portanto, a falta de humanidade atribuída a todas as populações não europeias é apresentada em atores imperiais, instituições e conhecimentos que tiveram a arrogância de decidir que certas pessoas que não lhes agradavam [ou que não gostavam deles], eram menos humanas. A corpo-política é um componente fundamental do pensamento descolonial, é um fazer descolonial e a opção descolonial para revelar, em primeiro lugar, as táticas da epistemologia imperial para afirmar a si mesma como humanitas do primeiro mundo desenvolvido e, por outro lado, levar o empreender da criação de saberes descoloniais que respondem às necessidades dos anthropos do mundo subdesenvolvido e em vias de desenvolvimento (MIGNOLO, 2010, p. 33). (Tradução livre minha) ${ }^{9}$

9 “Así, la corpo-política es el lado oscuro y la mitad faltante de la biopolítica que sólo es la mitad
de la historia: la corpo-política describe las tecnologías decoloniales aplicadas a cuerpos que se
dan cuenta que fueron considerados menos humanos, en el momento en que toman conciencia de
que el acto mismo de ser descritos como menos humanos era una consideración inhumana. Por Cadernos de estudos culturais, Campo Grande, MS, v. 2, p. 137-160, jul./dez. 2020. 
Posso afirmar que sou uma corpo-politica (MIGNOLO, 2010) evidenciada no meu fazer artístico, assim como no fazer docente, visto que as semelhanças entre o fazer artístico e o docente estão cada vez mais claras em minha mente, potencializando meu corpo primitivo contemporâneo e me fazendo enxergar o ser mais que sou na contemporaneidade. E isso independente da existência ou não de perfis com as minhas fotos, dados e diversos seguidores nas chamadas redes sociais. E é sobre essa potencialização que advém de um desprendimento do meu próprio pensamento referente ao meu corpo que se constituiu esta pesquisa, me proporcionando compartilhar o que relato a seguir.

\section{O MEU CORPO PRIMITIVO contemporâneo}

"E quando a dança acontece? Quando o corpo está disponível ao movimento para realizar uma comunicação através da expressão corporal, com a manifestação da dança de cada um" (MILLER, 2005, p.59). É dessa forma que entendo a dança hoje! Após um processo de quatro anos de estudos, entrega e aprendizado como discente do curso de licenciatura em Artes Cênicas na Universidade Estadual do Mato Grosso do Sul, Unidade Universitária de Campo Grande, posso afirmar que estou em um contínuo processo de desconstrução dos paradigmas estéticos, corporais e artísticos que me foram apresentados/construídos durante esses 29 anos.

Desde o meu início na graduação no ano de 2016 passei por diversas descobertas, sobretudo porque o curso é bivalente, contemplando as linguagens da Dança e do Teatro, onde a dança se configurou em mim a partir de um longo processo de aceitação e superação. Em contrapartida, fora do espaço acadêmico, meu corpo sempre teve muita afinidade com a linguagem, me levando a acreditar

ende, la falta de humanidad atribuida a las poblaciones no Europeas se presenta en actores imperiales, instituciones y conocimientos que tuvieron la arrogancia de decidir que, ciertas personas que no les gustaban, eran menos humanas. La corpo-política es un componente fundamental del pensamiento decolonial, el hacer decolonial y la opción decolonial al revelar, primero, las tácticas de la epistemología imperial para afirmarse a sí misma em la humanitas del primer mundo desarrollado y, por otro, al emprender la creación de saberes decoloniales que responden a las necesidades de los anthropos del mundo no desarrollado o en vías de desarrollo" (MIGNOLO, 2010, p. 33). 
que sempre dancei bem. Mas ao adentrar e fazer parte do corpo discente de um curso acadêmico de Dança, ou seja, o estudo da dança em um espaço acadêmico disciplinar, minha certeza passou a ser constantemente afetada, questionada e muitas vezes abalada.

Esses dias encontrei um meme que dizia "Tudo que eu pensava que fazia bem a faculdade me mostrou que não" e fiquei refletindo sobre como isso resume a sensação que tive por vários momentos; especialmente ao entrar em contato com os princípios da Dança e até mesmo com colegas que têm seus corpos treinados, imersos em técnicas totalmente exteriores à minha experiência de vida e de arte. Durante as aulas práticas de dança pude perceber que as diferenças entre os corpos, os treinados, dotados de técnicas corporais de movimento e os que estavam passando por aquele tipo de experiência pela primeira vez eram gritantes. Foi então que tive a consciência de que precisava de experienciação corporal, que não poderia me valer somente da teoria, até porque é na prática que a teoria se consolida.

Confesso que não foi uma consciência confortável. Precisei me desprender do meu próprio pensamento castrador que insistia em dicotomizar corpo e mente para, assim, me permitir a entender o corpo como uma unidade, sobretudo desconstruir a concepção de belo que me foi ensinada desde a infância: o belo grego que padronizou uma concepção de corpo em escala universal predominante até a contemporaneidade, solidificando um pensamento de dominação moderno que sempre condicionou as potencialidades biológicas instintivas como inferiores ao que tange a ciência, a racionalidade e mais atualmente aos avanços tecnológicos, mas que através da arte ganham uma nova configuração.

A partir da vivência nessas atividades, me lembro de sentir extrema dificuldade com a coordenação motora, não saber controlar o meu próprio corpo. Apresentava tensões nas escápulas, nas mãos, às vezes meu corpo tremia mesmo estando parado, excesso de energia. O tônus desequilibrado, movimentos exagerados, ritmo acelerado. O olhar era meio perdido, sem um foco. Sem falar dos problemas com as coreografias, apresentava uma extrema dificuldade em memorizar, sendo necessário repetir aos movimentos por várias vezes. Percebi uma mudança nesses fatores com o passar do tempo e das vivências em dança, só a partir da experiência do corpo consegui reverter esse quadro que segue em processo de desenvolvimento e aprendizado. 
Não conhecia o meu próprio corpo, não tinha consciência corporal, posso dizer que o reconhecia também como um recipiente, máquina, sempre me referindo a ele com o verbo "ter", "tenho um corpo", esquecendo que "sou um corpo". Mas como disse Thérèse Bertherat: "Nunca é tarde demais para liberar-se da programação de seu passado, para assumir o próprio corpo, para descobrir possibilidades até então inéditas" (BERTHERAT, 2010, p.12).

Essas possibilidades inéditas foram apresentadas a mim por meio da experiência do meu próprio corpo durante as aulas de dança, em especial quando tive contato com a educação somática e a técnica Klauss Vianna. Jussara Miller explica que a dança pode se tornar o fator de investigação do próprio corpo, convocando os princípios somáticos por meio da técnica Klauss Vianna:

A técnica Klauss Vianna propõe a ação criativa imbricada na ação técnica, ou melhor, o indivíduo em trabalho técnico está em ação investigativa de sua relação com o próprio corpo, com o corpo do outro e com o ambiente/espaço, com a percepção aguçada do momento/movimento. Por isso podemos falar de um "corpo em relação", ou seja, da atenção do corpo em relação ao todo, ao outro, ao espaço, ao ambiente numa rede de percepções (MILLER, 2012, p. 30).

É exatamente esse lugar de "corpo em relação" que (me) encontrei por meio da prática corporal, me levando a uma consciência outra a respeito de técnica e corpo, ou seja, hoje posso dizer que entendo a técnica como uma ferramenta de investigação, criação e expressividade que me proporciona uma consciência corporal e novos caminhos para a realização do movimento, potencializando as minhas sensibilidades e percepções. Por esta razão que me refiro ao corpo primitivo contemporâneo (meu próprio) como um corpo com elo entre instinto/sensibilidade/percepção/primitivo técnica/tecnologia/lógica/contemporâneo entendendo que o corpo se configura em uma unidade, uma soma que não perde suas potencialidades, mas que precisa de um resgate. Um corpo que precisa retomar sua Natureza mesma.

Esta consciência de ser corpo primitivo contemporâneo em constante fluxo me leva a entender a relação entre corpo, arte e tecnologia na cena visto que, a partir das relações estabelecidas entre tecnologia e dança, chegamos à contemporaneidade conscientes de uma concepção de corpo hiper-dimensionado. Corpos transformados em informação digital, fragmentados em telas, por projeções de imagens, prolongamentos e próteses acopladas ao corpo, me levando a pensar sobre a concepção de corpo grotesco de Ann Albright: 
Corpo grotesco é um corpo aberto, dilatado, estendido, em segredo, um corpo de devir, processo e mudança. O corpo grotesco opõe-se ao corpo clássico que é monumental, estático, fechado e limpo, correspondendo às aspirações do individualismo burguês (ALBRIGHT, 1997, p. 63). (Tradução livre minha) ${ }^{10}$

O corpo grotesco de Ann Cooper Albright para mim é o meu corpo primitivo contemporâneo que vive em constante processo de relação entre sensibilidade, percepção, técnica e tecnologia, ele não é um corpo clássico, monumental e não tão somente grotesco, mas sim o processo, a mudança, o conhecimento. Ele não é! Ele sempre está sendo, em constante fluxo de resignificação.

Encarar a linguagem da Dança em âmbito disciplinar me fez (re)verificar as concepções de arte, de cultura e de conhecimento, me levando a uma consciência de saber, sentir e ser um corpo da diferença cultural que vive em um mundo tecnocolonizado que precisa reverter as padronizações impostas através de discursos homogeneizantes que colonizam os corpos da contemporaneidade. $\mathrm{Ou}$ seja, é preciso despertar a consciência de que a tecnologia é a ferramenta e não a matéria biológica, e por meio das linguagens da arte isso pode ser feito, é por meio do teatro, da dança, das artes visuais e da música que os paradigmas são questionados e afetados. E ainda é através da prática em Arte que pude compreender as configurações do meu corpo primitivo contemporâneo. Sendo assim, compartilho do que Lúcia Matos (2012) diz:

Para a dança contemporânea, a quebra do unívoco e a busca pelo múltiplo abriram espaço para que se investigue novas configurações sobre o corpo que dança, que não estejam sustentadas pelos sistemas universalizantes do pensamento ocidental, como o pensamento cartesiano. O corpo dançante não é mais visto apenas em termos de sua relação cinética ou expressiva. Alguns coreógrafos procuram trabalhar/pesquisar o movimento, a sensação cinestésica ( sic), a fisicalidade, as idéias, a singularidade e as identidades daquele corpo específico que dança para que se possa reconhecer e incluir as diferenças, ressignificando, na dança, representações e metáforas construídas no/sobre o corpo (MATOS, 2012, p. 26-27).

\footnotetext{
10 "The grotesque body is the open, protruding, extended, secreting body, the body of becoming, process, and change. The grotesque body is opposed to the classical body, which is monumental, static, closed and sleek, corresponding to the aspirations of bourgeois individualism" (ALBRIGHT, 1997, p. 63).
} 
Embora a dança em contex to acadêmico tenha me levado a questionamentos onde duvidei das minhas próprias potencialidades, foi justamente esta experiência que me fez ampliar os horizontes me colocando frente a frente aos desafios de se permitir adquirir e produzir cultura e conhecimento por meio da arte. Levando-me a descobrir um corpo primitivo contemporâneo dotado de percepções e desejos que constituem e potencializam os meus processos criativos, teóricos e artísticos sem me preocupar diretamente com a falta de técnica que meu corpo apresentava, mas me colocando à disposição das imersões que me foram proporcionadas ao longo das disciplinas.

No decorrer da minha descoberta enquanto corpo que dança, tanto fora quanto dentro do contexto acadêmico, a tecnologia esteve sempre presente, me fazendo estar em constante pesquisa e principalmente questionar a minha relação com a tecnocolonização. Fato que me levou a pensar o uso de aparatos tecnológicos no meu cotidiano e consequentemente nos meus processos em arte, tanto que passei a utilizar o smartphone como uma ferramenta de auxílio nos meus estudos em dança. Passei a gravar os estudos de movimentos que tinha que apresentar. Gravei os estudos corriqueiros que fazia na universidade, em casa e até mesmo nas horas vagas em que eu simplesmente começava a dançar.

Por meio dos registros em vídeo, feitos com a câmera de um celular (figura 2), passei a encarar este aparato como um contribuidor que tenho a escolha de utilizar e que não silencia e anestesia a escuta do meu corpo, mas que está em constante troca, me levando a refletir sobre o que Silvia Wolff diz:

Corpo humano, biológico, fisiológico, dotado de músculos, sangue, vísceras, sinapses, instintos, desejos. Corpo localizado em um espaço, se colocando em uma realidade, em relação com outros (que também são indivíduos em relação). Corpo sensível, corpo físico, corpomídia, corpo social, corpo imagem, corpo identidade, corporeidade. As informações do meio se instalam no corpo; o corpo, alterado por elas, continua a se relacionar com o meio, mas agora de outra maneira, o que leva a propor novas formas de troca (WOLFF, 2013, p. 10). 


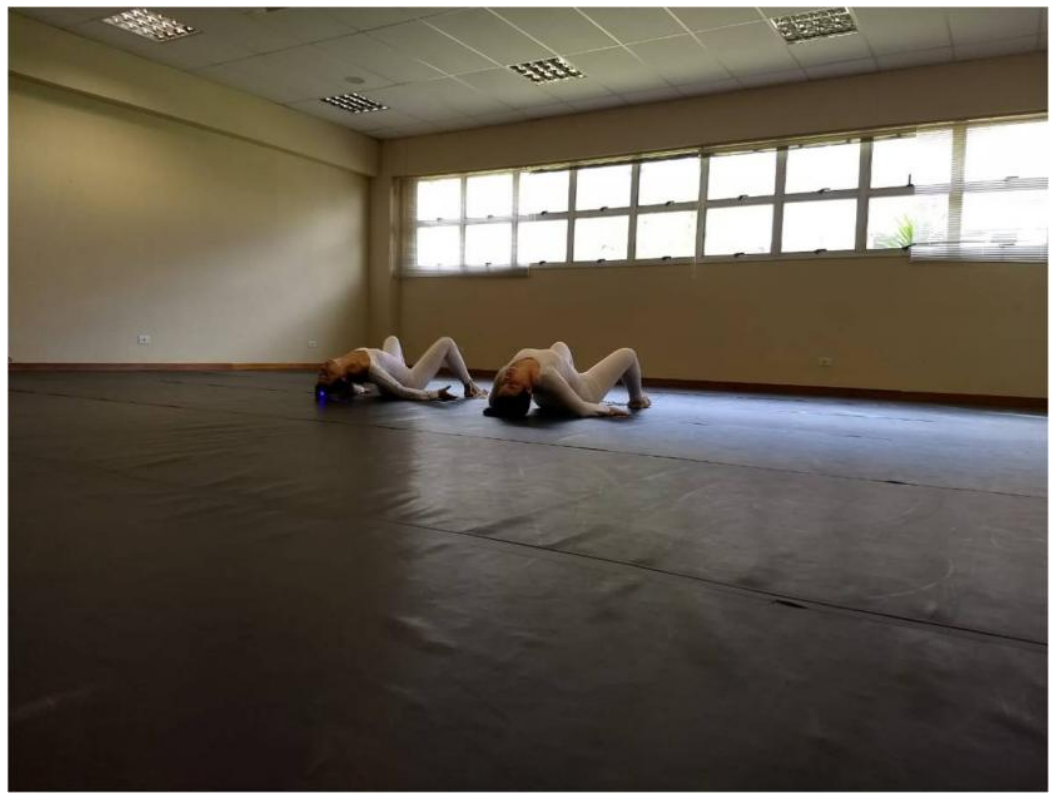

FIGURA 1. Corpos em experiência.

FONTE: Lana Figueiró (2018).

Sendo assim, posso afirmar que por meio das experiências e trocas que me foram oferecidas ao longo desses quatro anos de graduação descobri em mim um corpo primitivo contemporâneo que é corpo-política potencializado na cena artística, ocupando espaços e promovendo discursos que são considerados hereges em plena contemporaneidade. Mas um corpo que toma consciência desta condição quando acredita que é produtor de arte, de cultura e de conhecimento promovendo uma desobediência epistêmica (MIGNOLO, 2008) quando faz, sente e fala de si mesmo, evidenciando epistemologias por meio das suas biogeografias (BESSAOLIVEIRA, 2016) que os avanços tecnológicos não têm o poder de extinguir.

Com a consciência de que sou um corpo que sente, sabe e fala, deixo esses registros que foram feitos com a utilização de um computador, de fontes acessadas via internet, de inúmeras trocas via e-mail com o orientador, de dúvidas apresentadas via whatsapp, sobretudo de pensamentos, memórias, desejos e percepções de um corpo primitivo contemporâneo que vive em constante fluxo de troca e compartilhamento. Portanto, o meu corpo primitivo contemporâneo não é desumanizado, anestesiado, nem somente tecno(lógico), mecanicista e programado, é um corpo em estado de vida, consciente das suas múltiplas 
potencialidades. É o corpo que diz: Eu sinto, eu sei, eu falo, portanto, me resignifico, me liberto. Eu faço, eu posso, eu danço!

\section{CONSIDERAÇÕES FINAIS (Ainda que Parciais)}

Acredito que devemos promover um olhar diferenciado em relação à tecnologia, entendendo que devemos utilizá-la como uma ferramenta que nos auxilie, nos promova benefícios, sem subjugar nossos corpos biológicos aos poderes tecnológicos. Até porque o avanço tecnológico é obra de uma ação humana, de corpos biogeográficos (BESSA-OLIVEIRA, 2016) que pensam, sente, sabe e falam e que devem ser entendidos, assim, independente de suas diferenças culturais.

Não podemos negar que vivemos em um mundo tecnocolonizado onde a tecnologia se constitui em uma ferramenta de consumo e de poder. Contudo devemos cada vez mais estabelecer diálogos e trocas que promovam a conscientização de que somos corpos potencializados desde as suas capacidades perceptivas sensíveis às cognitivas, desestruturando o sistema universal moderno que insiste em ditar o que é arte, cultura e conhecimento colocando em detrimento os corpos que não se inscrevem nos meios tecno(lógicos): consequentemente considerados como não contemporâneos.

Por meio da minha prática e pesquisa em arte consegui despertar uma consciência outra enquanto corpo potente que produz conhecimento mesmo tendo como lócus enunciativo uma região que não é considerada um centro, promovendo uma desobediência da minha parte a todo um conjunto que afirma que sou um ser menos na contemporaneidade. Um sistema que pensa que pode falar das minhas capacidades melhor do que eu e que promove a tecnocolonização de corpos quando os condiciona à máquina.

Acredito que não somos corpos-dóceis mecanizados vivendo na contemporaneidade, aliás, fora as inúmeras dúvidas e questionamentos que esta pesquisa vem me proporcionando, só uma única afirmativa vem se consolidando cada vez mais em meu corpo: as teorias não dão conta de dizer o que é corpo. Corpo está para além do que podemos conceituar, assim como um corpo contemporâneo está para além de preceitos tecnológicos e do próprio tempo. Ao certo, quando voltarmos a compreender o corpo como razão e emoção juntos, 
como um corpo primitivo de fato, ainda que contemporâneo, teremos uma compreensão de corpo melhor do que as que temos hoje por meio de teorias que também são mecânicas e querem o corpo como máquina teórica.

\section{Referências}

AGAMBEN, Giorgio. O que é o contemporâneo? e outros ensaios. Tradução Vinícius Nicastro Honesko. Chapecó: Argos, 2009.

ALBRIGHT, Ann Cooper. Choreographing difference. The body and identity in contemporary dance. Hanover: Weslyan University Press, 1997.

BERTHERAT, Thérèse. O corpo tem suas razões: antiginástica e consciência de si. Com colaboração de Carol Bernstein; tradução Estrela dos Santos Abreu. 21 a. Ed. São Paulo: Editora WMF Martins Fontes, 2010.

BESSA-OLIVEIRA, Marcos Antônio. "Fronteira, biografia - biogeografias - como episteme descolonial para (trans)bordar corpos em artes da cena". In: Revista Conceição|Concept. Campinas, SP, v. 7, n. 1, jan./jun. 2018, p. 142-157. Disponível em: https://periodicos.sbu.unicamp.br/ojs/index.php/conce/article/view/8648471/18307. Acesso em: 06/ 03/2019.

BESSA-OLIVEIRA, Marcos Antônio. "O corpo que habito: esse não é o corpo da sala de aula, dos museus, nem o corpo da academia!". In: Acervo do autor. Campo Grande, MS, 2017, p. 1-15. (Texto no prelo).

BESSA-OLIVEIRA, Marcos Antônio. "(Trans)bordar Fronteiras: Estética Bugresca para Descolonizar Corpos Biogeográficos ”. In. Memória ABRACE XVI - Anais do IX Congresso da Associação Brasileira de Pesquisa e Pós-Graduação em Artes Cênicas. Anais... Uberlândia (MG) UFU, 2017b. Disponível em www.even3.com.br/anais/IXCongressoABRACE. Acesso em: 08/09/ 2019.

BESSA-OLIVEIRA, Marcos Antônio. "Biogeografias ocidentais/orientais: (i)imigrações do bios e das epistemologias artísticas no front". In: Cadernos de Estudos Culturais: Ocidente/Oriente: migrações. V. 8. N. 15. Campo Grande, MS: Ed. UFMS jan-jun., 2016. Disponível em: https://periodicos.ufms.br/index.php/cadec/article/view/3650/2912. Acesso: 25/09/2019.

FOUCAULT, Michel. Vigiar e Punir: nascimento da prisão. Trad. Lígia M. Ponde Vassalo. Petrópolis: Vozes, 1987.

GÓMEZ, Pedro Pablo. MIGNOLO, Walter. "Esteticas decoloniales: sentir, pensar, hacer en Abya yala y la gran comarca". In: GÓMEZ, Pedro Pablo. Estéticas decoloniales. 
[recurso electrónico]. Bogotá: Universidad Distrital Francisco José de Caldas, 2012, p. 623. Disponível em: https://adelajusic.files.wordpress.com/2012/10/decolonialaesthetics.pdf. Acesso em: 10/05/2019.

GREINER, Christine. "Em busca de uma metodologia para analisar a alteridade na arte". In: Revista Conceição I Concept. Campinas, SP, v. 6, n. 2, p. 10-21, jul./dez. 2017. Disponível em: https://periodicos.sbu.unicamp.br/ojs/index.php/conce/issue/view/1417/showToc. Acesso em: 06/11/2018.

GUERRA, Vânia Maria Lescano; NOLASCO, Edgar Cézar. (Orgs.). Michel Foucault: entre o passado e o presente, 30 anos de (des)locamentos. Campinas, SP: Pontes Editores, 2015.

KATZ, Helena; GREINER, Christine. "Por uma teoria do corpomídia". In: GREINER, Christine. O corpo: Pistas para estudos indisciplinares. São Paulo: Annablume, 2005.

MATOS, Lúcia. Dança e diferença. Salvador: EDUFBA, 2012.

MIGNOLO, Walter. "Desafios Decoloniais Hoje". In: Epistemologias do Sul. Foz do Iguaçu/PR, 1 (1), pp. 12-32, 2017. Disponível em: https://revistas.unila.edu.br/epistemologiasdosul/article/download/772/645. Acesso em: $22 / 03 / 2019$.

MIGNOLO, Walter. "Desobediência epistêmica: a opção descolonial e o significado de identidade em política". In: Cadernos de Letras da UFF: Dossiê: Literatura, língua e identidade, n.34, 2008, p. 287-324. Disponível em: www.uff.br/ cadernosdeletrasuff/34/traducao.pdf. Acesso em: 06/03/2019.

MIGNOLO, Walter. Histórias locais/ Projetos globais: colonialidade, saberes subalternos e pensamento liminar. Trad. De Solange Ribeiro de Oliveira. Belo Horizonte: Editora UFMG, 2003.

MIGNOLO, W. D. "Desobediencia epistémica II. Pensamiento independiente y libertad De-colonial." Otros Logos: Revista de Estudios Críticos, Neuquén, ano 1, n. 1, p. 8-42, 2010.

MILLER, Jussara. Qual é o corpo que dança? Dança e educação somática para adulto e crianças. São Paulo-SP, 2012.

MILLER, Jussara. A escuta do corpo: abordagem da sistematização da técnica Klauss Vianna. Dissertação de mestrado. Campinas: UNICAMP, 2005. Disponível em: http://repositorio.unicamp.br/jspui/bitstream/REPOSIP/285131/1/Miller_JussaraCorrea_ M.pdf. Acesso em 10/10/2019. 
PRENSKY, Marc. Digital Native, digital immmigrants. Digital Native immigrants. On the horizon, MCB University Press, Vol. 9, N.5, October, 2001. Disponível em: http://www.marcprensky.com/writing/Prensky\%20-

\%20Digital\%20Natives,\%20Digital\%20Immigrants\%20-\%20Part1.pdf. Acesso em: $11 / 10 / 2019$

RODRIGUES, Larissa; BESSA-OLIVEIRA, Marcos Antônio. "Corpos-tecno(lógicos) e a geopolítica da tecnocolonização". Texto no prelo, 2019.

SALVADOR, Gabriela Di Donato. A mitologia do corpo. In: VI congresso da ABRACE, 2010, São Paulo. Memória Abrace Digital, 2010. v. VI. Disponível em: http://portalabrace.org/vicongresso/dancacorpo/Gabriela\%20Salvador\%20-

\%20A\%20mitologia\%20do\%20corpo.pdf. Acesso em: 10/12/2019

SALVADOR, Gabriela Di Donato. Histórias e propostas do corpo em movimento: um olhar para a dança na educação. Paraná: ed. Unicentro, 2011.

SIMÃO, Marina Fazzio. Entre o corpo cotidiano e o corpo cênico: uma perspectiva pós-colonial. 2017. P, 23-24. Dissertação apresentada ao Programa de Pós- Graduação Intersisciplinar em Estudos Latino Americanos.Universidade Federal da Intregração Latino-Americana, Foz do Iguaçu, 2017. Disponível em: https://dspace.unila.edu.br/bitstream/handle/123456789/2737/Disserta\%c3\%a7\%c3\%a3o $\% 20-\% 20$ IELA\%20-

$\% 20$ SIM $\%$ c3\%830\%2c\%20Marina $\% 20 \mathrm{~F} . . p d f ?$ sequence $=5 \&$ isAllowed=y. Acesso em: $10 / 12 / 2019$.

SIQUEIRA, Denise da Costa Oliveira. Corpo, comunicação e cultura a dança contemporânea em cena. Campinas: Autores associados, 2006.

SNIZEK, A. B. "Corpo e identidade na dança contemporânea”. In; Revista de Ciências Humanas, Viçosa, v. 14, n. 1, p. 43-57, jan./jun. 2014. Disponível em: http://www.cch.ufv.br/revista/pdfs/vol14/artigo4vol14-1.pdf. Acesso em: 24/06/2018.

WOLFF, Silvia Suzana. Momento de transição: em busca de uma nova eu dança, 2010, 107 f. Tese (Doutorado em Artes) - Instituto de Artes. Universidade Estadual de Campinas, Campinas, São Paulo 2010.

Artigo recebido em: 17 de outubro de 2020. Artigo Aprovado em: 27 de dezembro de 2020. 